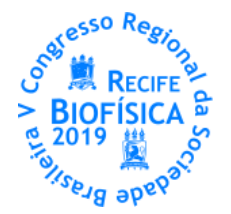

\title{
A IMPORTÂNCIA DO DIÁLOGO NO ENSINO DAS CIÊNCIAS POR INVESTIGAÇÃO
}

\author{
Gleidson Souza1, Romildo Nogueira², Thiago Araújo ${ }^{3}$
}

${ }^{1}$ Núcleo de Pesquisa e Estudos da Transdisciplinaridade (NUPET)-UFRPE, ${ }^{2}$ Laboratório de Biofísica Teórica -Experimental e computacional (LBTEC) e Núcleo de Pesquisa e Estudos da Transdisciplinaridade (NUPET) UFRPE, ${ }^{3}$ Grupo de Hermenêutica e Interdisciplinaridade na Formação de Professores (GHIFOP)-UFRPE

\section{INTRODUÇÃO}

O ensino por investigação é uma abordagem da educação em ciências que tem como base ensinar conceitos científicos a partir do estabelecimento de um problema para ser investigado. Este método visa o desenvolvimento de competências discentes por meio do diálogo entre sujeitos, mundo e ciência, do planejamento experimental e do uso do método científico, que permite os indivíduos estabelecerem e rejeitarem hipóteses, e aprender ciência fazendo ciência. Nesse texto, pretende-se discutir a importância do diálogo no ensino por investigação, estabelecendo a importância das interações discursivas entre professor-aluno e aluno-aluno na organização do conhecimento científico e, propor a Sequência Didática Interativa (SDI) como uma metodologia que efetivamente auxilia a promoção do diálogo científico.

Falar de ensino por investigação na qual o diálogo é um elemento primordial já é pregado por Freire (2001) na estrutura do processo de alfabetização que defendia. $\mathrm{Na}$ proposta freireana, os estudantes eram convidados a pesquisarem e perscrutar o seu universo vocabular, analisando, a partir dele, a diversidade, o impacto e as relações sociais existentes em torno dessas palavras. Para isso, o diálogo nas rodas de conversa era imprescindível. Os estudantes e os professores discutiam os temas geradores, pesquisavam em livros, materiais didáticos e na própria realidade social, e em seguida discutiam de forma horizontal e democrática os seus resultados e reinvindicações. Nesse processo, a relação entre a teoria e prática era desenvolvido e uma nova práxis social era estabelecida em função dos resultados das pesquisas em grupo. 0 tema ensino das ciências da natureza por projetos investigativos tem como marco o projeto de ensino de Física denominado Physical Science Study Committee (PSSC), iniciado na década de 60 nos EUA, sendo logo depois seguido de projetos para o ensino da Matemática (School Mathematics Study Group-SMSG), da Química (Chemical Bond Approach-CBA) e da Biologia (Biological Sciences Curriculum Study). Estes projetos de ensino gestados nos EUA tiveram uma grande repercussão no Brasil através dos Centros de Ensino de Ciências (CECl's), criados pelo MEC e com sedes em várias capitais brasileiras. Nesses CECl's os projetos americanos de ensino de Física, Química, Matemática e Biologia, após traduzidos para nossa língua, foram implementados e um trabalho de formação continuada nessas ciências foi realizado em várias capitais brasileiras. No entanto, a descontinuidade dos recursos para manutenção dos CECl's fez recuar este projeto para o ensino das ciências no Brasil. Apesar disso, o desenvolvimento deste projeto a nível nacional mostrou a possibilidade de se construir um projeto nacional em ensino de ciências no Brasil.

No final da década de 1990 , o sistema educacional brasileiro através do Ministério da Educação, elaborou os Parâmetros Curriculares Nacionais ( $\mathrm{PCN}$ ) e as Orientações Curriculares para o
Ensino Médio (OCEM), como proposta para subsidiar os docentes dispostos a mudarem sua prática baseada no modelo tradicional de transmissão-recepção. No entanto, um dos grandes entraves da educação no Brasil é resolver a dicotomia entre o modelo institucional de educação idealizados nos $\mathrm{PCN}$ e a real prática docente. De acordo com os PCN é preciso rever o papel da Educação, que é desenvolver pessoas com uma nova visão de conhecimento e aprendizagem e preparar os educandos para adaptarem-se as novas perspectivas da sociedade (BRASIL, 2000, 2006).

Com a proposta dos $\mathrm{PCN}$ se introduz a prática de utilizar os projetos de ensino para conduzir o processo de ensinoaprendizagem. Os PCN ao proporem a integração das disciplinas em áreas de conhecimentos através da realização de projetos interdisciplinares introduz na prática dos professores a ideia de projeto.

Nessa perspectiva o diálogo é a palavra de ordem no ensino por projetos, seja dos atores que participam desses projetos como das ciências envolvidas nessa prática interdisciplinar. Pensar o fazer, realizar algo refletindo suas consequências, em que o diálogo acontece para que os sujeitos compreendam suas necessidades individuais, as do outro e as do mundo, e participem na sua transformação deve ser o foco do ensino por projetos.

\section{0 diálogo em Freire}

Para Freire (1987), antes de qualquer recurso pedagógico, o diálogo é uma condição existencial. É pronunciando que se existe, é dizendo a palavra que eu posso ser, que tu podes ser, que nós podemos ser. É um assalto desumanizante que os sujeitos não consigam pronunciar a palavra.

Da mesma forma, o diálogo em Freire também é um encontro entre homens. Dessa conceituação, ressaltamos a nossa capacidade de nos reunirmos, para tratarmos do que é interesse nosso, mediatizados pelo mundo. Esse encontro é visto para o autor como um momento de solidariedade e liberdade na qual os sujeitos não lançam mão da conquista do outro.

No diálogo, também se vislumbra a possibilidade de ser mais. Ser mais implica ser uma presença no mundo, integrada com a presença de outros e a presença do próprio mundo. Dialogando, os sujeitos reconhecem-se participantes e responsáveis uns pelos outros e nisso, são ao mesmo interventores e transformadores do mundo.

Segundo Freire (1987) para que haja diálogo é necessário o amor, a humildade, a fé nos homens, a esperança e o pensar crítico. 0 amor não trata apenas do querer bem mútuo entre os homens, mas também da construção de uma relação de confiança entre eles para que possam dialogar o tornando-os sensíveis a questionar o 
mundo, como diz Freire, "se não amo o mundo, se não amo a vida, se não amo os homens, não me é possível dialogar" (FREIRE, 1987). A humildade é de grande importância para o diálogo, pois quando não há humildade há opressão, não há respeito, há arrogância. Um homem arrogante que não consegue partilhar e receber conhecimentos, não está apto a ouvir e a falar, ou seja, não consegue dialogar. Ser humilde é reconhecer que não há ignorantes absolutos, nem tampouco sábios absolutos, e ter a capacidade de perceber que é necessário caminhar juntos em comunhão, buscando cada vez saber mais (FREIRE, 1987). A fé nos homens é uma condição anterior ao diálogo, sem ela é impossível o diálogo. A fé que Freire defende refere-se à capacidade criadora, interventora e transformadora dos homens. A esperança trata da motivação para os processos transformadores. Não é possível dialogar na desesperança de que algo vá mudar, se os sujeitos do diálogo nada esperam do seu quefazer já não pode haver diálogo. 0 pensar crítico envolve a consciência da transformação possível do mundo e dos sujeitos dialogantes. Este pensar opõe-se à normatização dos seres humanos, à opressão, à falta de transformação e à pura adaptação, exigindo uma cultura de inquirição e permanente crítica dos espaços, processos e sujeitos. Uma vez fundamentado o diálogo, veremos como ele constitui a base necessária para o Ensino por investigação que defendemos.

\section{As interações discursivas no ensino por investigação.}

0 ensino por investigação tem como base aprender ciência fazendo ciência, ou seja, levando o aluno a pesquisar sobre o que se quer ensinar, tendo sempre à visão que o mais importante nesse processo investigativo não é somente a aprendizagem de conteúdos, mas a procedimental e a atitudinal, levando em conta todo o caminho trilhado na construção do conhecimento. (POZO; CRESPO, 2009)

Esse modelo não corresponde a uma imitação do trabalho dos cientistas no ambiente escolar, ele respalda uma metodologia que considera importante as etapas do método científico em função de um processo de função social de teorias e modelos.

No ensino por investigação algumas etapas são necessárias: 1. Despertar o interesse dos estudantes para o problema selecionado pelo professor; 2. Realizar um estudo qualitativo do problema, restringindo-o e estabelecendo variáveis; 3. Emitir hipóteses; 4. Elaborar e explicitar métodos para a solução do problema; 5. Aplicar o método; 6. Analisar os dados resolvidos; 7. Refletir as novas perspectivas abertas pelas soluções do problema (TRIVELATO; TONIDANDEL, 2015)

O nosso foco aqui será as interações discursivas, uma vez que é por meio do debate entre os participantes de uma pesquisa, que na maior parte das vezes os conhecimentos científicos são organizados.

Contudo, uma questão nos inquietam a partir do diálogo dentro do ensino por investigação:

Como o Ensino por investigação ajuda a promover a competência no educando para dialogar num mundo que não dialoga?

\section{METODOLOGIA}

Esta pesquisa utiliza uma abordagem qualitativa de pesquisa, que é realizada numa situação natural, com dados descritivos em abundância, e que possui plano aberto e flexível focalizado numa realidade complexa e contextualizada. (OLIVEIRA, 2005)

A metodologia proposta consistiu em preparar, executar e analisar uma proposta de Ensino por Investigação que utilizasse uma metodologia tipicamente dialógica em seus fundamentos, sem lançar mão de cumprir os preceitos dos fundamentos do modelo de ensino escolhido.

Abaixo fundamentamos e descrevemos a proposta utilizada.

\section{A Sequência Didática Interativa (SDI) numa perspectiva de} promover o diálogo.

A SDI surge a partir da necessidade de aplicar a metodologia interativa de Oliveira (2013) em contextos didáticos, permitindo que seus pressupostos básicos (hermenêutica, dialética, dialogicidade e complexidade) pudesse facilitar o processo de ensino-aprendizagem (OLIVEIRA 2013, p.58).

A SDI inspira-se teoricamente no circulo hermenêutico-dialético (CHD), e, portanto fundamenta-se nos seus preceitos:

É hermenêutica porque vai permitir que os indivíduos atuem dentro de um círculo "de compreensão" em que os seus construtos confrontam-se uns com os outros, numa tentativa de compreensão do outro, e ampliação e extrapolação da realidade interpretada.

É dialética porque permite que a contestação e as rupturas da realidade apareçam e sejam expressas, indicando que ela quase sempre é conflitiva, desigual e não conformativa.

- $\quad$ É dialógica porque é feita por momentos de encontros em que os sujeitos refletem sua própria realidade tal como a fazem e a refazem, por meio do diálogo durante todo o processo.

- É complexa porque tenta apreender o real na sua unidade e multiplicidade (unitas multiplex), pondo os sujeitos pensantes diante da exploração racional do imprevisível, do circular, do recursivo, longe da determinação causal e de tempo linear que tratam o racionalismo; integrando pensamento, objeto, ciência, tradição e cultura numa escala pluridimensional e transdisciplinar.

Como trabalhar com a SDI no contexto do Ensino por Investigação?

Como já estabelecemos no ensino por investigação deve-se: partir de problema definido; buscar as informações e os conhecimentos já existentes sobre o problema; reconhecer e se possível controlar as variáveis; levantar e testar as hipóteses formuladas; relacionar as informações e, finalmente, construir uma explicação para o fenômeno observado.

A SDI pode ser sistematizada nas seguintes etapas:

1. Construir individualmente explicações para o problema científico proposto;

2. Formar pequenos grupos de discussão para encontrar uma maneira de se chegar a uma síntese para explicação do problema;

3. Formar um grupo a partir dos representantes de cada grupo pequeno e formular uma síntese geral para explicação do problema;

4. Buscar aportes teóricos que possibilite respaldar a síntese geral formulada para explicação do problema;

5. Fechar a SDI com construção de textos, painéis, relatórios, artigos ou outras atividades pertinentes ao problema proposto.

A prática proposta acima permitirá que haja diálogo entre todos participantes deste processo de ensino-aprendizagem. Portanto, a SDI quando aplicada ao ensino por investigação tem como finalidade fomentar este diálogo. Portanto, estamos propondo aqui uma metodologia que permita o estabelecimento do diálogo entre os alunos envolvidos no processo de ensino por investigação, mediado sempre pelo professor.

\section{RESULTADOS E DISCUSSÃO}

\section{Uma abordagem prática do ensino por investigação}

Para contextualizar o ensino por investigação vamos trabalhar com a contraposição entre o senso comum e o método científico visando estabelecer hipóteses sobre o tempo necessário para uma bola de tênis atingir o solo após ser lançada horizontalmente ou em queda livre de uma altura determinada. Para realizar a atividade só 
necessitamos de uma bola de tênis e um celular (para filmar a queda da bola).

Inicialmente foram estabelecidas hipóteses sobre o tempo de chegada da bola ao solo. Duas hipóteses foram estabelecidas Ho (hipótese da nulidade): ambas chegam ao mesmo tempo no solo e a hipótese alternativa $\mathrm{H} 1$ : chegam em tempos distintos. Em seguida foram realizadas medidas do tempo necessário para bola atingir o solo (experimentos). Após os experimentos é possível aceitar ou refutar as hipóteses. Os procedimentos acima foram trabalhados com base na SDI e uma explicação negociada pelo grupo foi obtida para que o tempo de chegada ao solo fosse igual em ambos os casos. Aportes teóricos foram necessários para respaldar a síntese geral formulada para explicação do problema. Finalmente, foram redigidos em cada grupo relatórios descrevendo a experiência, os aportes teóricos e os resultados que permitiram uma explicação científica para o evento.

O problema descrito acima foi trabalhado numa sala de graduação do curso de educação física na disciplina de Biofísica com os alunos do terceiro período do curso.

Como estabelecido na SDI: numa primeira etapa (1) os alunos refletiram individualmente sobre o problema e em seguida sintetizaram seus pensamentos por escrito; numa outra etapa (etapa 2) foram formados quatro grupos de estudantes, cada um contendo 5 alunos, que dialogaram no interior do grupo e construíram um texto por grupo sobre a concepção deles com respeito ao problema proposto. Numa terceira etapa (3) cada grupo escolheu um representante que apresentou a concepção do grupo para todos os outros grupos. Finalmente, numa quarta etapa (4) foi regido um único relato negociado por toda turma.

Este procedimento foi realizado antes e após uma aula sobre os temas: método científico de Galileu e o estudo do movimento de projéteis e da queda livre dos corpos e o princípio da independência dos movimentos. Foi observado que antes da aula os relatos dos alunos tinham somente como base o senso comum e que mesmo assim apareceram respostas bastante interessantes. Por exemplo, dois grupos responderam que a bola lançada verticalmente chegava mais rápido que a outra lançada horizontalmente, porque esta última descrevia uma trajetória maior e, portanto, gastava mais tempo para realizar a sua trajetória. Esta resposta apesar de errada é bastante consistente do ponto de vista lógico. Os outros dois grupos responderam que as duas bolas chegavam ao mesmo tempo ao solo, devido ao fato que apesar das trajetórias serem diferentes ambas caiam sempre de uma mesma altura em cada etapa da trajetória. Esta resposta apesar de ser oriunda do senso comum tem uma base científica sólida como será discutida na aula teórica. Outras respostas foram discutidas e descartas pelos grupos por não acrescentarem informações relevantes ao tema em discussão.

Após uma aula sobre o método científico de Galileu e o estudo do movimento de projéteis e da queda livre dos corpos e o princípio da independência dos movimentos, os estudantes puderam associar a prática que eles realizaram aos princípios já estabelecidos na ciência. Desta forma, uma resposta ao problema negociado por toda a classe com respeito ao método científico foi de que o experimento realizado em sala de aula contemplava todas as etapas do método da indução experimental de Galileu, ou seja: 1. Observação dos fenômenos; 2 . Análise dos elementos que compõem os fenômenos; 3. Indução de hipóteses; 4. Verificação das hipóteses aventadas por intermédio das experiências; 5 . Generalização do resultado das experiências; 6. Confirmação das hipóteses obtendo-se leis gerais.

Com respeito ao estudo dos movimentos projéteis e da queda livre a discussão desses temas permitiu fundamentar teoricamente a proposta do senso comum que ambas caiam sempre de uma mesma altura em cada etapa da trajetória. Para o ensino destes temas foram discutidos textos da mecânica newtoniana e ministrada uma aula expositiva sobre o tema.

Com respeito ao uso da SDI para promoção do diálogo foi possível observar que todos os grupos conseguiram dialogar sobre o tema com bastante interesse. Em resposta a pergunta se a SDI viabilizou o processo discursivo todos os grupos responderam que o diálogo foi imediatamente estabelecido ao se formar os pequenos grupos de discussão, visando encontrar uma maneira de se chegar a uma síntese para explicação do problema. Em seguida, a formação de um grupo de representantes de cada grupo para formular uma síntese geral para explicação do problema permitiu que os estudantes apresentassem em público a ideia do seu grupo. Esta é uma nova competência que o aluno precisa adquirir para defender de maneira consistente a hipótese do seu grupo. Na busca dos aportes teóricos para respaldar a síntese geral formulada para explicação do problema foi trabalhado o diálogo científico, que estabelece uma nova linguagem para tratar o problema proposto em sala de aula. Finalmente, no fechamento da SDI foi usado a linguagem escrita na construção de textos, painéis, relatórios e artigos pertinentes ao problema proposto.

No exemplo acima acreditamos ter estabelecido como a SDI pode ser usada para permitir o diálogo no ensino por investigação.

\section{CONCLUSÕES}

1. No ensino por investigação as respostas advindas do senso comum são fundamentais para o processo discursivo;

2. A sequencia Didática Interativa (SDI) foi efetiva para promover o diálogo no ensino por investigação;

3. O ensino por investigação além de contextualizar o ensino de ciências por meio da pesquisa, permite o desenvolvimento de várias outras competências, tais como defender publicamente uma tese (ideia), aquisição de linguagem científica formal; elaborar relatórios (textos), painéis e artigos.

4. 0 uso da SDI respeita os preceitos estabelecidos para a educação problematizadora proposta por Freire (ANO) e permite que o respeito ao conhecimento prévio do estudante seja respeitado, ao passo que o conhecimento científico também seja construído, em diálogo constante entre tradição e cultura.

\section{REFERENCIAS}

BRASIL. MINISTÉRIO DA EDUCAÇÃO. Parâmetros Curriculares Nacionais: Ensino Médio. Brasília: MEC/SEF, 2000. . MINISTÉRIO DA EDUCAÇÃO. Orientações Curriculares para o Ensino Médio. Brasília: MEC/SEF, 2006.

FREIRE, P. À sombra desta mangueira. São Paulo: Editora Olho d'água. 2001

Pedagogia do oprimido. 17. ed. Rio de Janeiro: Paz e Terra, 1987.

OLIVEIRA, M. M. Sequência Didática Interativa: no processo de formação de professores. Petrópolis: Vozes, 2013.

. Como fazer pesquisa qualitativa. Recife: Bagaço, 2005.

POZO, J. I.; CRESPO, M. A. G. A aprendizagem e o ensino de ciências: do conhecimento cotidiano ao conhecimento científico. 5. ed. Porto Alegre: Artmed, 2009.

TRIVELATO, S.L.F.; TONIDANDEL, S.M.R. Ensino por investigação. Eixos organizadores para sequências de ensino de biologia. Revista Ensaio. Belo Horizonte. V.17 n. especial, p.97-114, 2015. 